\section{Wegener's granulomatosis and environmental factors in Western Montana}

\author{
Andrew Samuel Zeft, \\ Margaret H. Schlesinger, \\ Heather Keenan, ${ }^{1}$ Rod Larson, ${ }^{3}$ \\ Helen Emery, ${ }^{4}$ Noel S. Weiss ${ }^{5}$ \\ 'Department of Pediatrics, University \\ of Utah, Salt Lake City, UT; ${ }^{2}$ Adult and \\ Pediatric Rheumatology, Missoula, MT; \\ ${ }^{3}$ Rocky Mountain Center for Occupational \\ and Environmental Health, University of \\ Utah, Salt Lake City, UT; ${ }^{4}$ Department of \\ Pediatrics, University of Washington, \\ Seattle, WA; ${ }^{5}$ Department of \\ Epidemiology, University of Washington, \\ Seattle, WA, USA
}

\section{Abstract}

The objective of our study was to determine whether exposure to silica or other environmental factors is associated with developing Wegener's granulomatosis (WG), in a geographically isolated region of Western Montana. We sought to identify and interview all cases of WG diagnosed during 1993-2006 among residents of a ten-county region of Western Montana, as well as a group of demographically similar controls $(n=39)$ without autoimmune disease. In the interview, we ascertained occupational silica and other exposures (metals, solvents, pesticides, tobacco). We enumerated 32 cases of WG, of whom 27 were included in the case-control study. Overall, a history of silica exposure was not associated with WG $(0 \mathrm{R}=$ $0.68,95 \%$ CI: 0.13-3.27), although there was a suggestion of increase in risk among persons with relatively recent $(\mathrm{OR}=2.67,95 \% \mathrm{CI}$ : 0.54 17.2), heavy ( $\mathrm{OR}=1.82,95 \% \mathrm{CI}: 0.09-112.9)$, and prolonged $(\mathrm{OR}=1.53,95 \% \mathrm{CI}$ : 0.16-20.0) exposures. A history of having worked in the mining industry was associated with WG (six cases including three with no silica exposure, zero controls, lower 95\% CI: 1.53). Risk was not associated with occupational or aerial pesticide exposure, but with residential rodenticide use (OR=12.15, 95\% CI: 1.54-552). Occupational exposure to metals or solvents was not associated with WG, nor was a history of cigarette smoking. Results of earlier studies of WG support the hypothesis that silica exposure adversely influences the risk of developing WG. Our small study of WG failed to identify an association with silica overall, but the results are compatible with an increased risk in persons with relatively heavy, prolonged, and/or recent exposure.

\section{Introduction}

The antineutrophil cytoplasmic antibodyassociated vasculidites (AAVs) are a rarely occurring subset of autoimmune diseases. AAVs include the disorders Wegener's granulomatosis (WG), microscopic polyangiitis (MPA), and Churg-Strauss Syndrome. WG is a necrotizing, predominantly small vessel vasculitis characterized by granulomatous inflammation affecting primarily the upper airway, lungs, and kidneys. The characteristic renal pathology in AAV is pauci-immune extracapillary glomerulonephritis. Recently, an AAV classification system has been established, utilizing clinical and pathological features as well as the presence of cytoplasmic (cANCA) and perinuclear (pANCA) antineutrophil cytoplasmic antibody (ANCA), and the proteinase 3 (PR3) and myeloperoxidase (MPO) antibodies. ${ }^{1}$

Genetic susceptibility in WG is suggested by the presence of ethnic variation and familial aggregation, and by an association with specific genes. ${ }^{2}$ However, descriptive epidemiological studies identifying geographic variation, and other studies identifying seasonal differences in WG onset, have suggested that environmental factors also play a role in WG etiology. ${ }^{2-10}$ Environmental exposures can affect ANCA production. For example, persons with chronic exposure to ambient silica more commonly have elevated serum ANCA titers with MPO antibodies. ${ }^{3.4}$ In addition, the results of several case-control studies have suggested that occupational history of inhaled ambient silica is a risk factor for developing $\mathrm{AAV}^{5-8}$ Other case-control studies have observed an association between exposure to metals, solvents, and pesticides and AAV occurrence. ${ }^{8,11,12}$

While studies have identified the contribution of smoking to the development of rheumatoid factor and seropositive rheumatoid arthritis, studies of other immune-mediated disorders have failed to identify a clear influence of cigarette smoking on their development. ${ }^{13-15}$ The smoking prevalence in 197 patients with small vessel vasculitis and ANCA was observed to be lower than age-comparable values for the general population of Germany, suggesting that cigarette smoking could have a protective effect on disease development. ${ }^{16}$ However, a study comparing previous or current smoking history between 60 ANCA-positive patients and 120 ANCA-negative controls did not identify an association, ${ }^{17}$ nor did a study of 129 ANCA small vessel vasculitis cases and 109 population-based controls. ${ }^{5,6}$

The role of environmental factors in the development of autoimmune diseases is of particular concern in Western Montana where occupational asbestos exposures have been associated with acquiring both systemic autoimmune responses and various autoim-
Correspondence: Andrew Zeft, Assistant Professor of Pediatrics, Division of Allergy, Immunology, and Rheumatology, Department of Pediatrics, University of Utah School of Medicine, P.O. Box 581289, Salt Lake City, UT 84158-1289, USA.

E-mail: andrew.zeft@hsc.utah.edu

Key words: Wegener's granulomatosis, antineutrophil cytoplasmic antibody-associated vasculitis, environment, exposures, silica.

Contributions: AZ carried out the research and wrote the manuscript; MS and HE contributed to the study design and research methods; HK contributed to the study design and manuscript preparation; RL performed environmental occupational risk assessment; NW oversaw the study design and contributed to the manuscript preparation.

Conflict of interests: the authors report no conflicts of interest.

Received for publication: 11 August 2010.

Revision received: 22 November 2010.

Accepted for publication: 23 November 2010.

Acknowledgments: the authors would like to thank the physicians of Western Montana, and Richard Holubkov for his statistical assistance. This study was supported by The Vasculitis Foundation.

This work is licensed under a Creative Commons Attribution 3.0 License (by-nc 3.0).

(C) Copyright Zeft A.S. et al., 2010

Licensee PAGEPress, Italy

Rheumatology Reports 2010; 2:e8

doi:10.4081/rr.2010.e8

mune disorders. ${ }^{18,19}$ Recently, rheumatologists in Western Montana have expressed concern about the number of WG cases in their region, ${ }^{20}$ and many of their patients resided in small communities along the Clark Fork River where heavy metal contamination from mining activities is a regional environmental issue. $^{21}$

In our study reported here, we systematically identified cases of WG in an isolated region of Western Montana. To examine whether duration and intensity of exposure to silica and exposure to other environmental factors are associated with WG disease occurrence, we performed a case-control study.

\section{Materials and Methods}

\section{Subject identification}

Cases of WG and MPA were identified from the records of Saint Patrick's Regional Hospital 
in Missoula, MT, and Kalispell Regional Hospital in Kalispell, MT, and from the associated physician's offices. These two regional medical centers are the referral centers for a 10-county region of Western Montana, which geographically is isolated from outside specialty referral centers by the Rocky and Bitterroot mountain ranges (Figure 1). Cases diagnosed during 1993-2006 were identified retrospectively by verbal communication with all specialty physicians (rheumatologists, pulmonologists, nephrologists, otolaryngologists) within this region to whom patients with WG would be referred. In addition, death records from the MT State Department of Health (Helena, MT) were screened to identify persons who had resided within the 10county region and who had died of WG, using the International Classification of Disease-9Clinical Modification (ICD-9-CM) code $(446.0) .^{22}$

Potential controls had to reside in the study area, be discharged from one of the two regional medical centers between 1993 and 2006, and have no ICD-9-CM code identifiable for an autoimmune disease. Potential controls for each index case were randomly selected from this group by the following criteria: age \pm 5 years, sex, race, date of hospitalization within two years from date of index case diagnosis, and zip code of residence. After permission was granted either by the hospital physician or the subject's primary physician, case and control subjects were contacted by telephone, introduced to the study, and invited to participate. Of note, subjects discharged with a primary psychiatric diagnosis were excluded as potential control subjects. Additionally, local physician permission to contact potential control subjects who were discharged with an oncology diagnosis was not granted. No record was kept of potential controls who could not be contacted or who declined to be interviewed.

\section{Medical record abstraction}

A single rheumatologist reviewed individual case medical records to verify the diagnosis, based on a validated classification method. ${ }^{1}$ He then abstracted the following data: date of diagnosis, date of symptom onset, and zip code of residence at the time of symptom onset. Medical data collected for the time periods before and at the diagnosis of WG or MPA included reported symptoms, physical examination findings, and the results of laboratory, radiographic, and pathological studies.

\section{Interviews}

Occupational and residential exposure information in cases and controls was collected during a personal interview using a structured questionnaire modified from one devel-

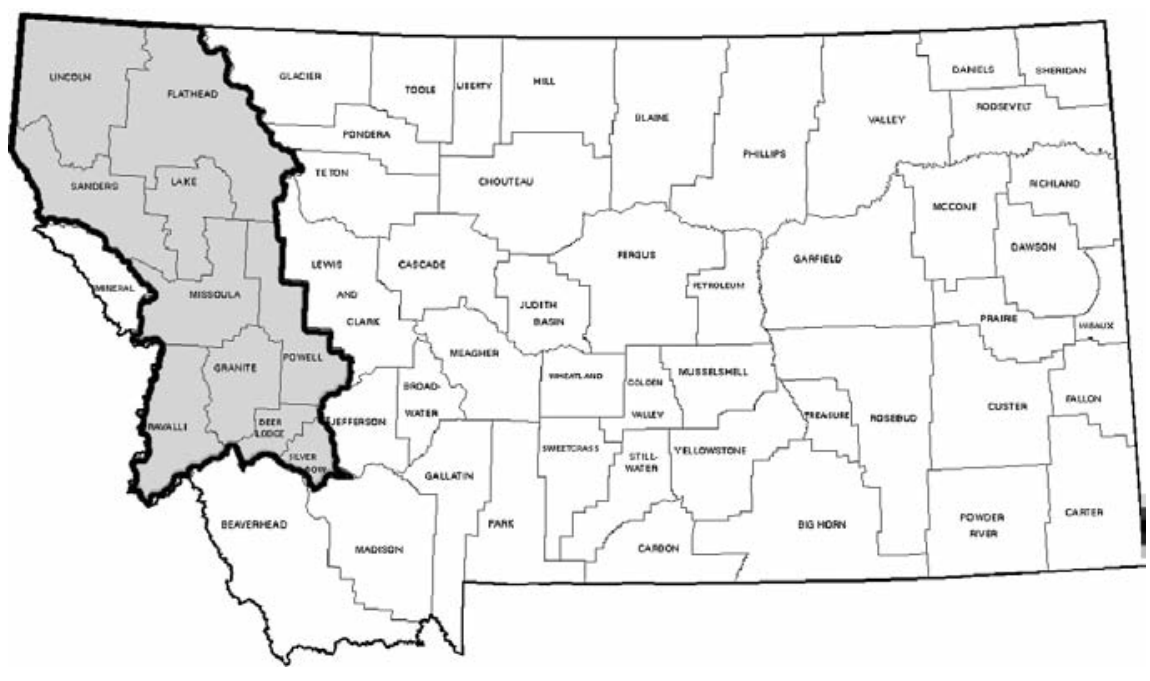

Figure 1 . Ten county study area of Western Montana.

oped and used in a case-control study of environmental factors and Parkinson's Disease.$^{23} \mathrm{~A}$ single interviewer, unblinded to the status of cases and controls, performed all interviews. In situations where the case or control was unable to give a reliable personal interview, exposure information was collected either via a next-of-kin relative or mailed questionnaire with follow-up telephone contact to clarify questions the subject had with the questionnaire's content. Exposure histories were sought prior to the date of subject-reported symptom onset of the case and to the same date in his/her control(s).

The determination of occupational ambient silica exposure was made by asking subjects whether they had ever worked in an occupation from a list, including stone crushing, tunnel drilling, sand blasting, and ceramic work. Direct questions ascertained the subject's history of work in the construction, mining, and smelter industries. Positive responses were followed by questions on the nature and duration of the occupational exposures (categorized into work-years) and the length or time worked weekly for the specific occupation-related task. A certified industrial hygienist blinded to the status of cases and controls assessed each subject's exposure intensity to occupational silica, which took into consideration the likely concentration, frequency, and duration of exposures. Each occupation that was associated with silica exposure was scored on the basis of the duration of exposure (fraction of years worked), multiplied by added weighted values for exposure intensity and exposure probability. ${ }^{24}$ Each job was assigned an exposure intensity representing the portion of exposure per total period of time worked per day $(\leq 10 \%=0.1$, $11 \%-20 \%=0.2, \quad 21-30 \%=0.3, \quad 31-50 \%=0.4$,
$>50 \%=0.5$ ). The exposure probability was 0.1 minimal, 0.25 for partial, 0.50 for $50 \%$ exposure, 0.75 for $75 \%$ exposure, and 1.0 for always exposed. Overall, cumulative scores were categorized as low exposure $(<0.1)$ and moderate-high exposure $(\geq 0.1)$. Evaluation of exposure to silica from agricultural sources accounted for the moderate level of silica in the typical agricultural sandy and clayey loam soils of Western Montana. ${ }^{25}$

Occupational exposures to metals, solvents, and pesticides were sought in a similar manner; subjects were asked whether they had worked in specific occupations known to yield exposure to these materials. For example, the assessment of metal exposure included the question, "Have you ever worked in any of the following industries: battery worker, chemist or chemistry technician, painter...fuel oil worker?" For pesticide exposure, the question was more direct, "Have you ever had a job (outside the home) where you worked with, handled, or were around pesticides, herbicides, insecticides, fungicides, or rodenticides (rat killers) at least once per week?" Further questioning enquired about direct occupational exposure to specific types of metals, chemical solvents, and pesticides; the question, "Have you ever had a job where you handled or came into contact with any of the following substances at least once per week?" was followed by the duration and degree of exposure to the individual compound. Subjects were asked if they had an occupation or industry involving inhalation of wood dusts, such as sawmill, carpentry, logging, and woodworking. Farming exposures were ascertained by asking subjects if they had "ever worked >6 months" in farming-related occupations. Residential exposure to pesticides was ascertained by asking, "Have you ever 
used pesticides, herbicides, or fungicides around your home, on your pets, or in your garden for killing insects or pests?" The subject's residential water source (well, city) at the date of the cases symptom onset was ascertained. The subject's history of direct contact with Clark Fork River water (swimming, wading, or fishing $>5 \mathrm{x} /$ year for $>5$ years) was ascertained. The subject's prior residential distance $<1$ mile from a chemical factory, stone quarry/gravel plant, or agricultural area sprayed with pesticides was ascertained. Personal smoking and tobacco chewing history were assessed.

\section{Statistical analysis}

Odds ratios (OR) and 95\% confidence intervals (CI) were calculated by exact conditional logistic regression to estimate the strength of association between WG and the environmental exposures measured. Data were analyzed using LogXAct Version 7, Cytel Software (Cambridge, MA, USA).

\section{Results}

We identified $36 \mathrm{AAV}$ cases (32 WG, 4 MPA). Three AAV cases were identified solely by a physician's verbal report, and informed consent was not obtained from these subjects to allow formal chart review. Of the remaining 33 AAV cases, 29 were classified as WG and the remaining four were classified as MPA.

Using the 2000 population census of the 10 county region of Western Montana $(\mathrm{n}=319,639)$, the 2006 point prevalence per 105 of AVV was 10.0 (95\% CI: 9.9-10.1), of WG 9.1 (95\% CI: 9.9-10.1), and of MPA 1.3 (95\% CI: 1.1-1.4).

Demographics of cases and controls (age, gender, race) are provided in Table 1.

Discharge diagnosis of the controls included cardiovascular disease (38\%), orthopedic referral (26\%), other injury (18\%), obstetrics (5\%), otolaryngology procedure $(5 \%)$, hernia surgery (3\%), urological stones (3\%).

Table 2 presents the estimated risk (and $95 \% \mathrm{CI}$ ) of developing WG associated with the occupational silica exposures examined.

A history of occupational silica exposure (ever) was present in 17 cases (63\%) and 27 controls $(69 \%)$, corresponding to an odds ratio of 0.68 (95\% CI: $0.13-3.27)$. A history of occupational silica exposure in the year prior to symptom onset was present in eight cases (30\%) and seven (18\%) controls, corresponding to an odds ratio of 2.67 (95\% CI: 0.54 17.25). There was a suggestion of a modest increase in risk associated with medium-high exposure to silica and with long duration of exposure, but the confidence intervals around the risk estimates were extremely wide.
Similarly, although a positive relation between a history of silica exposure and WG was seen in men $(\mathrm{OR}=2.72,95 \% \mathrm{CI}$ : 0.49 $15.2)$ and a negative one in women $(\mathrm{OR}=0.21$, 95\% CI: 0.037-1.16), the tiny numbers available for sex-specific comparisons argue for a cautious interpretation. Six cases but no controls reported having worked as miners at some point in their lives (OR=infinity, 95\% CI: 1.53-infinity). Specific mining-related activities included tunnel drilling $(\mathrm{n}=3)$, sand blasting $(n=1)$, stone crushing $(n=1)$, and arsenic exposure. The median employment duration in these exposed cases was 7 years (range 0.3-15 years). Only one of the six cases had worked in the mining industry in the year prior to symptom onset. There was little or no association between occupational exposure to metals, solvents, pesticides, and farming with the occurrence of WG (Table 3).

Table 4 presents the estimated risk (and $95 \% \mathrm{CI}$ ) of developing WG associated with the residential exposures examined.

A history of residential exposure to rodenticide was present in seven (26\%) cases and one (3\%) control, corresponding to an odds ratio of 12.15 (95\% CI: 1.54-552.03). The individual rodenticide most commonly identified was an anticoagulant (d-Con; $n=3$ ). A history of residential exposure to insecticide was present in 21 (78\%) cases and 21 (54\%) controls, corresponding to an odds ratio of 2.26 (95\% CI: 0.76-7.55). Individual insecticides most commonly identified were organophosphates (diazinon $n=5$, malathion $n=4$ ) and

Table 2. Occupational silica exposure measures of cases and controls.

\begin{tabular}{lcccc} 
Silica exposure & No. of cases & No. of controls & Adjusted ratio & $95 \%$ CI \\
Never & 10 & 12 & 1 & -- \\
Ever & 17 & 27 & 0.68 & $0.13-3.27$ \\
\hline Recent & 8 & 7 & 2.67 & $0.54-17.2$ \\
Past & 9 & 20 & 0.35 & $0.06-1.41$ \\
\hline Low intensity & 6 & 15 & 0.41 & $0.07-1.91$ \\
High intensity & 11 & 12 & 1.82 & $0.09-112.9$ \\
\hline Short duration* & 5 & 17 & 0.48 & $0.07-2.64$ \\
Long duration & 12 & 10 & 1.53 & $0.16-20.01$ \\
\hline
\end{tabular}

${ }^{*}$ short duration ( $>0-3$ work-years), long ( $>3$ work-years).10

Table 3. Non-silica occupational exposures of cases and controls.

\begin{tabular}{lcccc}
$\begin{array}{l}\text { Occupational } \\
\text { exposure }\end{array}$ & $\begin{array}{c}\text { No. of exposed } \\
\text { WG cases }(\mathrm{n}=27)\end{array}$ & $\begin{array}{c}\text { No. of exposed } \\
\text { controls }(\mathrm{n}=39)\end{array}$ & Odds ratio & $95 \% \mathrm{CI}$ \\
Metal & 10 & 13 & 1.3 & $0.31-5.65$ \\
Pesticide & 3 & 11 & 0.18 & $0.004-1.52$ \\
\hline Solvent & 11 & 23 & 0.54 & $0.18-1.50$ \\
Inhalation & 13 & 17 & 1.35 & $0.40-4.87$ \\
\hline Mining & 6 & 0 & infinity & 1.53 -infinity \\
Construction & 7 & 10 & 1.18 & $0.24-6.36$ \\
\hline Smelter & 1 & 4 & 0.32 & $0.006-3.32$ \\
Farming & 17 & 23 & 1.22 & $0.35-4.23$ \\
\hline
\end{tabular}

chlorinated hydrocarbon (DDT; $n=3$ ). There was little or no association with exposure to residential herbicides or fungicides, occupational handling of pesticides, or a history of residential exposure to aerial pesticide application. Precision was poor for all estimates secondary to the small sample size.

A history of residence within a mile of a chemical factory or plant emitting exhaust was present in four (15\%) cases and two (5\%) controls, corresponding to an odds ratio of 2.56 (95\% CI: 0.36-29.0). There was no association with a history of inhalation-related occupational exposures.

Elevated risk was not associated with a history of cigarette smoking, even relatively heavy smoking. A history of pipe smoking was present in five (19\%) cases and three (8\%) controls, corresponding to an odds ratio of 5.77 (95\% CI: 0.53-295).

Table 1. Demographics of Wegener's granulomatosis cases and controls.

\begin{tabular}{lcc} 
& $\begin{array}{c}\text { WG } \\
(\mathbf{n = 2 7})\end{array}$ & $\begin{array}{c}\text { Control } \\
(\mathrm{n}=39)\end{array}$ \\
$\begin{array}{l}\text { Age, mean } \pm \text { SD (years) } \\
53 \pm 19\end{array}$ & $51 \pm 20$ \\
Sex (\% male) & 61 & 63 \\
\hline Race (\% Caucasian) & 93 & 100 \\
\hline *Two of the 29 classified Wegener's granulomatosis (WG ) cases \\
were not included in the case-control study (controls not avail- \\
able).
\end{tabular}




\section{Discussion}

We investigated potential associations of occupational and residential environmental exposures with the development of WG in an isolated region of Western Montana. The primary hypothesis addressed by this study was whether prior occupational silica exposure intensity and duration was associated with the development of WG, as silica exposure had previously been identified in prior case-control studies of occupational exposure in $\mathrm{AAV}^{5-8}$ The results of our regional case-control study neither strongly support nor refute this hypoth esis. Gregorini et al. examined 16 male patients with ANCA rapidly progressive glomerulonephritis (RPGN) and randomly sampled 32 gender-, age- ( \pm 5 years), hospitaladmission date-matched controls with nephropathies other than ANCA RPGN. ${ }^{7}$ Occupational histories were obtained by an industrial hygienist blinded to the status of cases and controls and silica exposures were based on the duration $>6$ months and the degree of individual exposure. The authors reported a 14-fold greater risk of glomerulonephritis in silica-exposed patients (OR=14.1, 95\% CI: 1.7-113.8). Similar to our case-sample, four of the seven silica-exposed subjects had exposure from mining-related occupations. Nuyts et al. examined 16 predominantly male patients with WG, meeting American College of Rheumatology (ACR) criteria and biopsy-confirmed pauci-immune focal segmental glomerulonephritis or a history of dialysis treatment, and 32 age-, gender, region-matched population controls. ${ }^{26}$ Occupational exposure was scored by an industrial hygienist who rated exposure degree and frequency, but not duration. The authors reported a five-fold greater risk of WG $(\mathrm{OR}=5.0,95 \% \mathrm{CI}$ : 1.4-11.6) in silica-exposed patients. Rihova et al. examined 31 patients with AAV and pulmonary involvement, 22 of whom had WG as per the Chapel Hill Consensus Conference (CHCC) definition, and 30 age-, gender-, residence-matched controls. Written questionnaires determined each subject's level and duration of exposure to silica-containing chemicals including asbestos. Seven AAV patients had low-level exposures (four silicone dioxide, three asbestos; mean 4 years), and the control group had none. Hogan et al. compared 65 cases of AAV and biopsyproven pauci-immune necrotizing glomerulonephritis, and 65 gender-, age-, race-matched controls with biopsy-proven renal disorders other than AAV. Occupational inhaled silica exposures, determined by questionnaire, were $>1$ year of exposure. Forty-six percent of cases reported silica exposure compared with $20 \%$ of controls (OR=4.4, 95\% CI: 1.36-13.4). ${ }^{6}$ Eightythree percent of exposed cases reported $>2$

Table 4. Residential and tobacco exposures of cases and controls.

\begin{tabular}{lcccc} 
Exposure & $\begin{array}{c}\text { No. of exposed } \\
\text { WG cases }(\mathrm{n}=27)\end{array}$ & $\begin{array}{c}\text { No. of exposed } \\
\text { controls }(\mathrm{n}=39)\end{array}$ & Odds ratio & $95 \% \mathrm{CI}$ \\
City water & 13 & 15 & 1.53 & $0.47-5.36$ \\
Well water & 13 & 24 & 0.54 & $0.14-1.85$ \\
\hline Clark Fork River & 8 & 14 & 0.85 & $0.16-4.17$ \\
Pesticides (any) & 3 & 11 & 0.18 & $0.004-1.52$ \\
\hline Insecticides & 21 & 21 & 2.26 & $0.76-7.55$ \\
Herbicides & 17 & 23 & 1.14 & $0.37-3.74$ \\
\hline Rodenticides & 7 & 1 & 12.15 & $1.54-552$ \\
Fungicides & 1 & 2 & 0.62 & $0.01-12.3$ \\
\hline Residence $<1$ mile from & & & & \\
Chemical factory & 4 & 2 & 2.56 & $0.36-29.03$ \\
Quarry or gravel plant & 6 & 12 & 0.55 & $0.15-1.75$ \\
Aerial pesticide & 16 & 20 & 1.35 & $0.48-4.01$ \\
Any tobacco & 15 & 19 & 1.5 & $0.36-7.29$ \\
Cigarette & 12 & 19 & 0.76 & $0.20-2.76$ \\
$\quad$ low (>0, <5 pack-years) & 3 & 3 & 1.37 & $0.17-10.85$ \\
$\quad$ high ( $>5$ pack-years) & 9 & 16 & 0.56 & $0.11-2.53$ \\
Pipe (cigar) & 5 & 3 & 5.77 & $0.53-295.4$ \\
Chew & 3 & 4 & 1.12 & $0.14-8.84$ \\
\hline
\end{tabular}

years of exposure.

Recent studies have examined more closely the effect of silica exposure intensity on WG presentation. Lane et al. studied 47 cases of WG diagnosed by ACR and CHCC criteria and 220 gender-, age-matched inpatient and outpatient hospital controls with non-inflammatory musculoskeletal diseases. ${ }^{8}$ A single interviewer unblinded to the status of cases and controls assessed occupational silica exposures primarily in the year prior to case symptom onset using a job exposure matrix. The risk of acquiring WG and MPA in those categorized with high silica exposure was 2.5 (95\% CI: 0.8$8.5)$ and 3.2 (95\% CI: 0.8-8.5), respectively. There was also a relationship of AAV to jobs of $>480$ months (OR=2.63, 95\% CI: $1.03-6.73)$. More recently, a case-control study by Hogan $e t$ al. examined lifetime occupational silica exposure by the same method we have in our study, comparing exposure dosage, duration, and intensity in 129 patients with AAV biopsyproven pauci-immune necrotizing glomerulonephritis and 109 randomly selected, regionalbased, age- and gender-matched controls. ${ }^{5} \mathrm{An}$ occupational hygienist and epidemiologist assessed individual exposures. There was no association with low/medium exposure relative to no exposure $(\mathrm{OR}=1.0,95 \% \mathrm{CI}$ : 0.4-2.2), but moderate increase in risk was identified with high exposure (OR=1.9, 95\% CI: 1.0-3.5). This study further suggested that long duration of silica exposure ( $>21$ years) is associated with the development of ANCA-SVV (OR=2.3, 95\% CI: 1.0-5.3). As in our study, MPO-ANCA specificity was more common among those exposed to high silica compared with all other cases ( $67 \%$ vs. $40 \%)$, and lung involvement was similar between cases with high and either low or no silica exposure (51\% vs. $45 \%$ ). The results of our study also suggest that non-silica mining-related occupations might be associated with an increased risk of developing WG. Three of the six cases with prior mining occupations had involved silica, but otherwise there were no unifying exposures identified in these subjects. The majority of cases exposed to mining occupations did not have ANCA-MPO antibodies, in contrast to a finding from other series in which serum MPO-ANCA antibodies were prevalent in mine workers. ${ }^{3,4}$ However, the three WG cases in our study exposed to the highest silica all had MPO-ANCA antibodies. Beaudreuil et al. have compared exposure intensity in 60 ANCA-positive patients, 20 with WG and 120 hospitalized, age- $( \pm 5$ years $)$, gender-matched controls. ${ }^{17}$ They found that patients with the highest category of silica exposure had the highest risk of ANCA positivity (OR=6.9, 95\% CI: 1.33-35.1), but they found no difference in silica exposure in subject groups identified by ANCA subtype.

Mining-related occupational exposures are diverse, and have been shown to have many untoward health effects. ${ }^{27}$ The influence of mining exposures on autoimmune disease pathogenesis has been largely attributed to the effects of inhaled silica. ${ }^{28}$ However, multiple exposures often occur in mining operations, thus confusing this presumption. Descriptions of the autoimmune disease, progressive systemic sclerosis, in gold-mine workers were first reported by Erasmus in 1957, ${ }^{29}$ and further studies have identified the increased risk of male mine workers for developing systemic sclerosis and rheumatoid arthritis. ${ }^{30,31}$ A high prevalence of systemic lupus erythematosus (SLE) has been identified in uranium miners 
exposed to silica ${ }^{32}$ In addition, in a retrospective cohort study of 2414 male gold-miners who had worked underground $>1$ year, Calvert et al. examined the incidence of those treated for end-stage renal disease (ESRD) compared with that of the US population. ${ }^{33}$ Risk was greatest for ESRD owing to glomerulonephritis or interstitial nephritis, for which the standardized incidence ratio was 4.22 (95\% CI: 1.54-9.19), increasing to 7.70 (95\% CI: 1.59 22.48) among workers with $>10$ years of employment underground. Furthermore, a study of 52,277 cases and 260,632 controls obtained from death certificates identified that mortality risk from autoimmune diseases, specifically rheumatoid arthritis (OR=1.3, 95\% CI: 1.1-1.5) and SLE (OR=1.2, 95\% CI: 1.0-1.4), is increased in patients previously exposed to mining as determined by the occupational code "mining machine operator" on the subject's death certificate. ${ }^{34,35}$ Most recently, a Swedish population-based case-control study of 2288 WG patients diagnosed by ICD\#9 hospital discharge code and gender-, age-, regionmatched controls (10 per case) identified borderline risk $(\mathrm{OR}=1.6,95 \% \mathrm{CI}$ : 0.8-3.1) for miners after a validation step excluded cases not fulfilling ACR criteria. ${ }^{36}$

We observed a positive association of exposure to rodenticides and a weakly positive association of exposure to insecticides with the development of WG. It is difficult to make inferences on these associations because risk from occupational and residential aerial pesticide exposures was not seen. However, another case-control study of 101 WG patients and 54 healthy controls identified an increased risk $(\mathrm{P}=0.046)$ associated with occupational pesticide exposures (defined as working in an area for $>4$ hours where pesticides had been sprayed). ${ }^{12}$ Lane et al.'s case-control study in the UK of 46 WG cases and 220 controls identified farming as a risk factor $(\mathrm{OR}=2.7,95 \% \mathrm{CI}$ : 1.3-5.7), suggesting that pesticide exposures acquired through farming could play a role in disease development. ${ }^{8}$ However, Hogan et al.'s 2007 study did not identify this association, but a positive association was identified with crop harvesting (OR=2.5, 95\% CI: 1.1-5.4), an exposure more closely identified with silica exposure. ${ }^{5}$ Mechanisms by which pesticides might influence the development of autoimmunity have not been clearly identified. ${ }^{37}$ However, it is worth noting that organophosphates have been shown to increase antibody responses in mice and administration of Malathion to the autoimmune-prone murine strain MRL-lpr accelerates autoantibody production, as well as the number of inflamed glomeruli and the appearance of proteinuria. ${ }^{38}$

Our study did not identify positive associations with prior cigarette smoking. Our results are similar to those of most other case-control studies of WG and AAV.,
The prevalence of WG in Western Montana can be compared to other regions within the northern hemisphere. The 2008 point prevalence in the United Kingdom was 13.0/10 while the 1994 prevalence in northern Germany was $5.8 / 10^{5} .^{39,40}$ The high ratio of WG to MPA in our study is also consistent with what has been seen in other northern European populations. ${ }^{9}$

Our study has many limitations; most notable are its small sample size, crude means of exposure ascertainment compounded by the need to enquire about events which occurred years prior to the disease onset event, subject nonparticipation, and recall bias inherent in obtaining a retrospective exposure assessment in persons diagnosed with having a serious disease such as WG compared with more healthy controls. Additionally, confounding of multiple concurrent exposures is an issue when utilizing occupationally characterized exposure measures. The validity of the control group is uncertain, largely since approximately one-third of controls had a known history of coronary artery disease. Coronary artery disease is also an inflammatory-mediated disease, and studies have shown associations with occupationally mediated inhalation exposures. ${ }^{41,42}$

In conclusion, our small study of WG failed to identify an association with silica overall, but the results are compatible with an increased risk in persons with relatively heavy, prolonged, and/or recent exposure. A larger study would have allowed for more robust risk estimates. The results of our study should be placed in the context of results from earlier studies of WG, which support the hypothesis that silica exposure adversely influences the risk of developing WG.

\section{References}

1. Watts R, Lane S, Haslik T, et al. Development and validation of a concensus methodology for the classification of the ANCA-associated vasculitides and polyarteritis nodosa for epidemiologic studies. Ann Rheum Dis 2007;66:222-7.

2. Mahr AD, Neogi T, Merkel PA. Epidemi ology of Wegener's granulomatosis: Lessons from descriptive studies and analyses of genetic and environmental risk determinants. Clin Exp Rheumatol 2006;24:S82-91.

3. Wichmann I, Sanchez-Roman J, Morales J, et al. Antimyeloperioxidase antibodies in individuals with occupational exposure to silica. Ann Rheum Dis 1996;55:205-7.

4. Bartunkova J, Pelclova D, Fenlova Z, et al. Exposure to silica and risk of ANCA-associated vasculitis. Am J Ind Med 2006;49:569-
76.

5. Hogan SL, Cooper GS, Savitz DA, et al. Association of silica exposure with antineutrophil cytoplasmic autoantibody small-vessel vasculitis: a populationbased, case-control study. Clin J Am Soc Nephrol 2007:2:290-9.

6. Hogan SL, Satterly K, Dooley MA, et al. Glomerular Disease Collaborative Network. Silica exposure in anti-neutrophil cytoplasmic autoantibody-associated glomerulonephritis and lupus nephritis. J Am Soc Nephrol 2001;12:134-42.

7. Gregorini G, Ferioli A, Donato F, et al. Association between silica exposure and necrotizing crescentic glomerulonephritis with p-ANCA and anti-MPO antibodies: a hospital-based case-control study. Adv Exp Med Biol 1993;336:435-40.

8. Lane SE, Watts RA, Bentham G, Innes NJ, Scott DG. Are the environmental factors important in primary systemic vasculitis? A case-control study. Arthritis and Rheum 2003;48:814-23.

9. Ntatsaki E, Watts RA, Scott DG. Epidemiology of ANCA-associated vasculitis. Rheum Dis Clin N Am 2010;36:44761.

10. Chen M, Kallenberg CM. The environment, geoepidemiology and ANCA-associated vasculitides. Autoimmun Rev 2010;9:A2938.

11. Albert D, Clarkin C, Komoroski J, Bresinger CM, Berlin JA. Wegener's granulomatosis: Possible role of environmental agents in its pathogenesis. Arthritis Rheum 2004:51:656-64.

12. Duna GF, Cotch MF, Galperin C, Hoffman DB, Hoffman GS. Wegener's granulomatosis: role of environmental exposures. Clin Exp Rheumatol 1998;16:669-74.

13. Klareskog L, Padyukov L, Alfredsson L. Smoking as a trigger for inflammatory rheumatic diseases. Curr Opin Rheumatol 2007;19:49-54.

14. Boyko EJ, Koepsell T, Perera DR, Inui TS. Risk of ulcerative colitis among former and current cigarette smokers. $\mathrm{N}$ Engl $\mathrm{J}$ Med 1987:316:707-10.

15. Young KA, Parrish LA, Zerbe GO, et al. Perinatal and early childhood risk factors associated with rheumatoid factor positivity in a healthy paediatric population. 2007;66:179-83.

16. Haubitz M, Woywodt A, de Groot K, Haller $\mathrm{H}$, Goebel U. Smoking habits in patients diagnosed with ANCA-associated small vessel vasculitis. Ann Rheum Dis 2005;64:1500-2.

17. Beaudreuil S, Lasfargues G, Laueriere L, et al. Occupational exposure in ANCA-positive patients: a case-control study. Kidney Int 2005;67:1961-6.

18. Noonan CW, Pfau J, Larson TC, Spence 
MR. Nested case-control study of autoimmune disease in an asbestos-exposed population. Environ Health Perspect 2006;114: 1243-7.

19. Pfau JC, Sentissi J, Weller G, Putnam EA. Assessment of autoimmune responses associated with asbestos exposure in Libby, Montana, USA. Environ Health Perspect 2005;113:25-30.

20. Feigley P. Letter to Peggy Schlesinger from the State of Montana Department of Health and Humane Services, 2002.

21. Moore JN, Luoma S. Hazardous wastes from large-scale metal extraction. Environ Sci Technol 1990;24:1278-85.

22. International Classification of Diseases, Ninth Revision Clinical Modification: ICD9-CM. 6th ed. Los Angeles, 2001.

23. Firestone JA, Smith-Weller T, Franklin G, et al. Pesticides and risk of Parkinson disease: a population-based case-control study. Arch Neurol 2005;62:91-5.

24. Diot ELV, Guilmot JL, Metzger MD, et al. Systemic sclerosis and occupational risk factors: a case-control study. Occup Environ Med 2002;59:545-9.

25. Stopford CM, Stopford W. Potential for respirable quartz exposure from North Carolina farm soils. Scan J Work Environ Health 1995;21:S44-6.

26. Nuyts GD, Van Vlem E, De Vos A, et al. Wegener granulomatosis is associated to exposure to silicon compounds: a casecontrol study. Nephrol Dial Transplant 1995;10:1162-5.

27. Pratt DS. Occupational health and the rural worker: agriculture, mining, and logging. J Rural Health 1990;6:339-417.

28. Parks CG, Conrad K, Cooper GS. Occupational exposure to crystalline silica and autoimmune disease. Environ Health Perspect 1999;107:S793-802.

29. Cowlie RL, Dansey R. Features of systemic sclerosis (scleroderma) in South African gold miners. SA Med J 1990;77:400-2.

30. Baur X, Rihs HP, Altmeyer P, et al. Systemic sclerosis in German uranium miners under special consideration of autoantibody subsets and HLA class II alleles. Respiration 1996;63:368-75.

31. Turner S, Cherry N. Rheumatoid arthritis in workers exposed to silica in the pottery industry. Occup Environ Med 2000;57:4437.

32. Conrad K, Mehlhorn J, Luthke K, Dorner T, Frank KH. Systemic lupus erythematosus after heavy exposure to quartz dust in uranium mines: clinical and serological characteristics. Lupus 1996;5:62-9.

33. Calvert GM, Steenland K, Palu S. End-stage renal disease among silica-exposed gold miners. A new method for assessing incidence among epidemiologic cohorts. JAMA 1997;277:1219-23.

34. Gold LS, Ward M, Dosemeci M, De Roos AJ. Systemic autoimmune disease mortality and occupational exposures. Arthritis Rheum 2007;56:3189-201.

35. Steenland K, Brown D. Mortality study of gold miners exposed to silica and nonasbestiform amphibole minerals: an update with 14 more years of follow-up. Am J Ind
Med 1995;27:217-29.

36. Knight A, Sandin S, Askling J. Occupational risk factors for Wegener's granulomatosis: a case-control study. Ann Rheum Dis 2010;69:737-40.

37. Holsapple MP. Autoimmunity by pesticides: a critical review of the state of the science. Toxicol Lett 2002;127:101-9.

38. Rogers SW. Reconstructing the behaviors of extinct species: An excursion into comparative paleoneurology. Am J Genet A 2005;134:349-56.

39. Watts RA, Mooney J, Scott DGI. A twenty year study of the epidemiology of ANCA associated vascultiis in UK [abstract]. APMIS Suppl 2009;1117(Suppl 127):159.

40. Reinhold-Keller E, Zeidler A, Gutfleisch J, et al. Giant cell arteritis is more prevalent in urban than rural populations: results of an epidemiological study of primary systemic vasculitides in Germany. Rheumatology 2000;39:1396-402.

41. Gustavsson P, Plato N, Hallqvist J, et al. A population-based case-referent study of myocardial infarction and occupational exposure to motor exhaust, other combustion products, organic solvents, lead, and dynamite. Stockholm Heart Epidemiology Program (SHEEP) Study Group. Epidemiology 2001;12:222-8.

42. Gustavsson P, Alfredsson L, Brunnberg H, et al. Myocardial infarction among male bus, taxi, and lorry drivers in middle Sweden. Occup Environ Med 1996;53:23540. 